A Variance Decomposition of the Continuous Assessment of Interpersonal Dynamics

Sydney E. Fox ${ }^{1}$, Katherine M. Thomas ${ }^{2}$, C. Emily Durbin ${ }^{3}$, \& Christopher J. Hopwood ${ }^{1}$

${ }^{1}$ University of California, Davis, Department of Psychology

${ }^{2}$ Center for Therapeutic Assessment

${ }^{3}$ Michigan State University, Department of Psychology

In press: Psychological Assessment

Please address correspondence regarding this article to Christopher J. Hopwood, UC Davis chopwoodmsu@gmail.com 


\begin{abstract}
The Continuous Assessment of Interpersonal Dynamics (CAID) is an observational coding method that enables continuous tracking of warmth and dominance in both members of a dyad as an interaction unfolds. Research using this tool has revealed dynamic patterns relevant to psychopathology and psychotherapy, suggesting considerable potential for clinical assessment and research. However, CAID data are sensitive to a variety of person and situational factors, and the way that these factors combine to influence CAID data is poorly understood. We examined data from ten raters using CAID to assess moment-to-moment warmth and dominance in opposite-sex married dyads ( $N=137$ couples) interacting in four distinct situations. Using Generalizability Theory methods, we decomposed sources of variance in CAID data and estimated multiple forms of between- and within-person reliability. Results revealed how spouses' moment-to-moment behaviors varied as a function of person, sex, dyad, rater, situation, and relevant interactions between these factors. Based on these results, we provided guidelines for interpreting CAID data at different levels of aggregation in clinical research and practice.
\end{abstract}

Keywords: Interpersonal; Circumplex; Dyadic; Time Series; Generalizability Theory; Assessment; Relationships; Dynamics 
Many theories about personality, psychopathology, psychotherapy, and social relations emphasize the importance of dynamic patterns of interpersonal behavior in human functioning (e.g., Pincus et al., 2009; DeYoung \& Krueger, 2018; Fonagy et al., 2018; Lorenzo-Luaces et al., 2015; Lipsitz \& Markowitz, 2013). However, most interpersonal assessment tools are designed to capture broad behavioral trends in isolation from their social context (e.g., Locke, 2011). Although there has been a recent increase in approaches that capture interactions in respondents' daily lives (e.g., Wright \& Zimmermann, 2019; Trull \& Ebner-Priemer, 2013; 2014; Sadikaj et al., 2010), these approaches generally summarize each interpersonal interaction with a single assessment and thus fail to capture dynamics that occur as an interpersonal situation unfolds.

The Continuous Assessment of Interpersonal Dynamics (CAID; Sadler et al., 2009) is an observational tool in which streams of interpersonal behavior are captured as a continuous stream while people interact. Data collected using this instrument have revealed a number of novel and important findings about individual differences (Hopwood et al., 2020), social transactions (Markey et al. 2010), and psychological dysfunction (Assaad et al., 2019; Lizdek et al., 2016), and thus CAID has considerable promise for applied clinical assessment (e.g., Thomas et al., 2014; Tracey et al., 2012). However, as a relatively new device, the factors that influence variation in CAID parameters remain poorly understood. The purpose of this study was to examine the most commonly reported CAID parameters using Generalizability Theory analyses in a sample of couples who interacted in four different situations, with the goal of better understanding the information provided by CAID and thus informing the interpretation of CAID data in future research and practice.

\section{Interpersonal Assessment}

A large body of research spanning several decades has shown that interpersonal behaviors can be organized using the Interpersonal Circumplex (IPC; Figure 1; Leary, 1957; Wiggins, 1979, 1991; Pincus \& Ansell, 2003; Locke, 2011). The IPC is structured by two orthogonal dimensions. The vertical 
dimension, agency, captures variation from dominance to submission. The horizontal dimension, communion, captures variation from warmth to coldness. Variation from the center of the circle to the edge of the circle reflects the intensity of behavior, whereas variation around the circle indicates the nature or quality of behavior (e.g., warm vs. warm-dominant vs. dominant; Leary, 1957).

This measurement framework has been used to study a variety of interpersonal domains at different times scales, using different methods. Questionnaires have been developed to assess traits, problems, sensitivities, tactics, goals, strengths, values, and efficacies, among other domains (Locke, 2011). Sophisticated approaches have been developed to interpret differences between these levels of interpersonal behavior for clinical assessment (Dawood \& Pincus, 2018). These questionnaires have been administered in both self- and informant-report format, the discrepancy between which has proven to be clinically important in some cases (Pincus et al., 2019; Liso et al., 1994; Cooper et al., 2012).

A central premise of interpersonal theory and many other models of personality, psychopathology, and psychotherapy, though, is that important features of people and relationships are missed in static averages. Yet, reliable patterns of behavior have been more difficult to identify and measure than relatively stable characteristics, in part because of the traditional focus on assessment instruments that emphasize what people are like in general, rather than how people change from one moment to the next. For instance, the instruments described in the previous paragraph could be used to reliably indicate how dominant a person tends to be, relative to other people, across many situations, but would not directly inform the contexts in which the person becomes more or less dominant, or the situations in which dominance may be maladaptive. The last few decades of research have witnessed a significant increase in Ecological Momentary Assessment (EMA) tools designed to measure people multiple times over relatively short intervals (Stone \& Shiffman, 1994; Beal \& Weiss, 2003; Shiffman et al., 2008; Ebner-Priemer \& Trull, 2009; Wright \& Zimmerman, 2019). Notably, much of this research measures the interpersonal variables dominance and warmth in some form. This research has begun to 
yield important information about clinical processes that unfold from one situation to the next with significant applied potential.

However, these methods are not designed to assess potentially important features of interpersonal processes that occur as situations unfold. This leaves considerable interpersonal territory unexplored. For instance, a core tenet of interpersonal theory, complementarity, asserts that the behaviors of one person invite particular behaviors from the other person (Kiesler, 1996; Sadler et al., 2009); accordingly, hypotheses have been developed about how deviations from complementarity may be associated with psychopathology (Pincus \& Hopwood, 2012; Wright et al., under review) or important therapeutic processes (Tracey et al., 2012; Thomas et al., 2014). Complementarity is generally thought of as a transaction that occurs while people interact. Thus, estimating complementarity requires data that captures variation within interactions (Tracey et al., 2004). The focus of this paper is on an instrument designed to capture interpersonal variation as people with interact with one another, the Continuous Assessment of Interpersonal Dynamics (CAID).

\section{Continuous Assessment of Interpersonal Dynamics}

The CAID system (Lizdek et al., 2012; Sadler et al., 2009) is an observational method in which raters continuously assess and track warmth and dominance throughout an interaction using a computer joystick. CAID has been used to measure social dynamics in married couples (Lizdek et al., 2016; Assaad et al., 2019), patient and therapist dyads (Altenstein et al., 2013; Hopwood et al., 2016; Pincus et al., 2014, 2019; Thomas et al., 2014), patients and their partners (Ross et al., 2017), mother and child dyads (Klahr et al., 2013), and unacquainted undergraduates (Markey et al., 2010; Sadler et al., 2009). These studies reveal microprocesses that may be overlooked in data from more molar alternative measures of interpersonal behavior. For instance, Lizdek, Woody, Sadler, and Rehman (2016) found that couples with depressed husbands tended to have interactions that became progressively colder and disengaged as the conversation unfolded. In another study, Altenstein, Krieger, and Grosse-Holtforth 
(2013) observed that potentially alliance-threatening emotional arousal increased when therapists and patients were less complementary on dominance. Both of these studies imply clear and concrete strategies for improving relationships and thus exemplify the value of repeated measurements of interpersonal behavior as interactions unfold.

Several parameters can be computed from CAID data. The mean level of warmth represents the aggregated scores of warmth for an individual across all moments during the interaction; similarly, overall mean level of dominance represents the aggregated dominance scores. These values reflect how warm and dominant each person was, on average, and thus are analogous to the values obtained from a single interaction in a typical event-contingent EMA design (e.g., Moskowitz \& Sadikaj, 2012). Unlike in EMA data, within-situation variabilities can also be computed around these means. Variability estimates indicate the degree to which the individual varies from their mean level across moments during an interaction. For example, two people may be highly variable in their level of dominance when working on a task together, reflecting that each person takes turns being in charge and is thus submissive sometimes and dominant others. Conversely, a parent may tend to stay relatively dominant throughout an interaction with their child in which they aim to maintain the authoritative position.

Other values reflect temporal associations between variables as the interaction unfolds. The correlation between time and warmth or dominance indicates whether the person being coded changed their position linearly as the interaction unfolded. For instance, people may become colder and more dominant as an argument "heats up". It is common practice to regress time out of CAID time series and compute correlations with residual warmth and dominance values. This allows the resulting correlations to be interpreted in terms of momentary fluctuations, independent of overall trends (Sadler et al., 2009). The within-person correlation between warmth and dominance time series indicates whether an individual becomes warmer as they become dominant (a positive correlation) or as they become more submissive (a negative correlation). This deviation from the normative tendency for warmth and 
dominance to be orthogonal, or only mildly correlated, has been referred to as shape (Fournier et al., 2010; Thomas et al., 2014).

Lastly, complementarity can be computed with CAID data as either as the mean-level similarity between aggregated warmth and dominance scores, or as the correlation between warmth and dominance time series across dyadic partners as the situation unfolds. Although the term complementarity has been used to describe both mean-level and moment-to-moment behavioral processes, there seems scarce reason or research to suggest that mean-level and moment-to-moment behaviors should reflect the same processes (Sadler et al., 2011). For instance, two partners who both tend to be highly extraverted (i.e., warm and dominant; see Figure 1), and thus do not complement one another's mean-level dominance, may nonetheless naturally negotiate power dynamics in their relationship as their interactions unfold, and thus complement one another's dominance from one moment to the next.

Overall, CAID allows for a rich depiction of moment-to-moment levels of and shifts in interpersonal behavior that has not been previously possible in other IPC-based measures. However, as a relatively novel method, the aspects of interpersonal interactions that most strongly impact CAID ratings remain poorly understood. This constrains the applicability of CAID for clinical assessment and research. A particular concern is the degree to which inferences can be made about people or dyads, in general, from data that were collected in one specific situation (e.g., Boon-Falleur et al., 2020; Hedge et al., 2018; Woods \& Wright, 2019). In this study, we use Generalizability Theory (Cronbach et al., 1963) analyses to decompose the sources of variance in CAID ratings. This allows for a determination of how much various factors, such as cross-situational individual or dyadic differences, situations, or raters, influence CAID parameters. The goal is to provide researchers and clinicians with a firmer basis for interpreting these kinds of data.

\section{Generalizability Theory}


Generalizability Theory (GT; Cronbach et al., 1963) is an extension of classical test theory capable of estimating the influence of different sources of potential variance in observed test scores. The procedural layout of GT is comprised of two consecutive sets of analyses termed the "G study" and "D study". In the G study, all possible sources of variation are isolated and their influence on CAID parameters are estimated (Shavelson \& Webb, 2005). Potential influences on individual variables, such as mean-levels of dominance, include stable characteristics of the person or dyad, the theme of the situation, gender, or variation among raters. Distinguishing the relative influences among these kinds of sources can be critical for interpreting CAID scores. As an example, if variation in mean-levels of dominance across people is determined primarily by a stable personality disposition, there may be little advantage to trying to capture situational influences. Conversely, if differences in raters account for most of the reliable variation in dominance scores, researchers might reconceptualize CAID as a perceptual task rather than an interpersonal coding paradigm, because this finding would suggest that the data reveal more about raters than targets. The sources of variance in interpersonal behavior we are interested in estimating in this study are person, sex, dyad, raters, situation, and their interactions.

In the D study, equations based on these variance components are used to estimate the reliability of different kinds of CAID-based inferences (Brennen, 2001; Cronbach \& Shavelson, 2004; Shavelson et al., 1989). For instance, D study results can be used to determine how many situations should be observed in order to make inferences about stable personality features, or the likelihood that differences from one situation to the next reflect important features of those situations. Taken together, $\mathrm{G}$ and $\mathrm{D}$ study analyses enable researchers to parse sources of variance in warmth and dominance ratings provided by CAID, identify these sources and distinguish them from measurement error, and then evaluate results of CAID assessments based on the extent to which each of these sources influence the ratings.

\section{Study Aims}


The general aim of this study is to apply GT to CAID data to determine the factors that influence different CAID parameters (G study) and the reliability of different kinds of inferences based on CAID data (D study). Both the CAID system itself and the application of GT to CAID data are too novel to inform confident and specific predictions about the G study results, and thus we did not make any confirmatory hypotheses. Utilizing these estimates, the results from the D study will guide future assessors with respect to the amount and type of data they would need to collect in order to test different kinds of hypotheses and will indicate which kinds of interpretations can and cannot be made reliably. For instance, can we conclude that a person who is cold in one stressful interaction is cold in general? Or do we need data from both stressful and relatively stress-free interactions to make a reliable inference about their overall coldness? D study analyses were also exploratory.

\section{Methods}

\section{Participants}

We used data collected from opposite sex couples ( $N=274 ; 137$ dyads) recruited from the Chicago, IL area for a study on family relationships, temperament, and psychopathology (see previous papers using this sample: Stroud et al., 2010; Stroud et al., 2011; Wilson \& Durbin, 2012a; Wilson \& Durbin, 2012b; Assaad et al., 2019). We coded video-recorded interactions collected during the second laboratory visit of this study during which parents engaged in multiple discussion tasks. Participants were mostly (93\%) married $^{1}$ (length of marriages: $M=8.81$ years, $S D=3.96$ years) and ranged in age from 23-57 years (women $M=36.91 ; S D=5.17 ;$ men $M=38.27 ; S D=5.79$ ). For reasons related to broader study goals, all couples cohabited and had at least one biological child between the ages of 3-6 $(M=2.32$ children; $S D=0.88)$. Among participants who provided information on their race/ethnicity (90\%), most described themselves as Caucasian/White (75.9\% women, $75.5 \%$ men), followed by Hispanic/Latino (10.2\% women, 11.3\% men), African-American/Black (9.3\% women, 9.4\% men), Asian

\footnotetext{
${ }^{1}$ For ease of communication, we refer to participants as husbands and wives throughout the paper.
} 
(8.3\% women, $4.7 \%$ men), Native American ( $2.8 \%$ women, $1.9 \%$ men), bi/multi-racial ( $1.9 \%$ women, $3.8 \%$ men), and "other than listed" ( $1.9 \%$ women, $4.7 \%$ men), and within-couples spouses typically endorsed the same race/ethnicity (80.4\%). Among couples who provided information on their family income (86.4\%), $1.9 \%$ reported income below 10,$000 ; 17.8 \%$ reported income between 21,000 and 40,000; $15.0 \%$ reported income between 41,000 and 60,$000 ; 31.8 \%$ reported income between 61,000 and 100,000; and 33.6\% reported income above 100,000. All study procedures were approved by local Institutional Review Boards and families were paid for their participation.

\section{Procedures}

During their lab visit, couples engaged in four distinct discussions tasks. As the "warm-up" discussion, couples were told to plan a real or imagined vacation ( $\sim 5$ minutes), discussing the location, length, and activities involved with their potential trip. For their "cool-down" discussion, couples were asked to discuss the best things about their relationship ( $\sim 5$ minutes). Between these tasks, couples engaged in two conflict discussions ( 8 minutes each), one identified as the wife's conflict and the other identified as the husband's conflict (counter-balanced across couples), in which research assistants instructed participants to thoroughly discuss selected disagreements, chosen based on the couples' combined two most highly rated areas of disagreement on the Dyadic Adjustment Scale (DAS; Spanier, 1976), and to try to reach a solution. Although these situations do not cover the full range of normative situations (e.g., Sherman et al., 2015; Parrigon et al., 2017), the tasks were designed to elicit common but specific emotional experiences that often occur between romantic partners (Foster et al., 1997), and they provide a valuable avenue for examining behaviors across distinct socio-emotional contexts.

\section{Observational Assessments}

Trained raters assessed couples' moment-to-moment warmth and dominance across conversations using the Continuous Assessment of Interpersonal Dynamics (CAID; Lizdek et al., 2012; Sadler et al., 2009). To assess ongoing interpersonal behaviors during couples' conversations, raters 
were trained to make continuous, behaviorally anchored ratings of each person's warmth and dominance during each discussion using the CAID. Ratings were made by simultaneously viewing a discussion and using a computer joystick ${ }^{2}$ to code each target's behaviors twice per second. Consistent with past research, CAID data were scaled from -1000 to 1000 on both dimensions, with 1000 on the yaxis representing extreme dominance and 1000 on the $x$-axis representing extreme warmth (see Figure 1).

Raters were instructed to code behaviors by moving the joystick in accord with all of the target's statements, nonverbal behaviors, fluctuations in tone, etc., that constituted an increase or decrease in warmth and/or dominance. As such, raters moved the joystick continuously in accord with their perceptions of changes in the target's interpersonal behavior. Example behaviors for each dimension are as follows: dominant behaviors included directing the conversation, asserting authority, and speaking during conversational lulls; submissive behaviors included following the other person's lead, adhering to requests, and not speaking during conversational lulls; warm behaviors included physical gestures such as moving closer to the other person, eye contact, and affectionate touching, and verbal communications such as laughing, praising, supporting, or complimenting the other person; and distant behaviors included physical gestures like looking away or aggressive touch, verbal communications such as cruel or critical comments, and an absence of reciprocated warmth, such as not laughing when the other person used humor or withdrawing from physical affection. Because behaviors often reflect a blend of warmth and dominance (e.g., withdrawals are often cold and submissive), horizontal and vertical joystick movements often occur simultaneously to varying degrees, and raters were instructed to move the joystick in a manner that concurrently represented warmth and dominance. Raters were instructed to code even slight gestures like eye contact, head nods, and changes in tone to ensure we captured fine-grained variations in behavior. When no discernible changes in behavior were displayed,

\footnotetext{
${ }^{2}$ In this study we used the Microsoft SideWinder Force Feedback 2, without force feedback applied.
} 
raters were instructed to maintain their most recent joystick position until the target displayed a meaningful interpersonal behavior. However, sometimes a lack of behavioral change is interpersonally meaningful, such as when a person does not respond to another person's question.

A total of 10 undergraduate research assistants, five female and five male, provided observational ratings for this study. At any given time, there was a team of eight raters, four female and four male; however, two male raters participated in this two-semester study for one semester each (providing approximately half of the codes relative to other raters), and one (female) coding trainer (KMT) rated $20 \%$ of the interactions as part of ongoing reliability checks. Raters were trained using protocol outlined by Sadler and colleagues (2009; see also Lizdek et al., 2012 and https://osf.io/5dh9r/?view_only=60e0fff4cf21477ebc597b72a64d843f) and only began coding study videos after achieving sufficient reliability on at least five training videos.

Raters were assigned to code dyads using the following guidelines: 1) two males and two females coded every discussion, and 2) each rater coded either the vacation or the best things discussion and either the husband conflict or the wife conflict discussion for each couple. Raters assigned to a discussion coded both the husband and the wife (one male and female coded the wife first and one male and female coded the husband first). This approach was taken to reduce the likelihood that observed differences between husbands' and wives' behaviors within an interaction were an artifact of different raters' unique perceptions or systematic biases. Raters received four distinct coding assignments, completed by situation in the following order: 1) vacation, 2) husband conflict, 3) wife conflict, and 4) best things. Each rater was assigned to approximately half of the couples in each category. The order in which raters watched videos was randomized to reduce the influence of potential rater drift systematically affecting some couples more than others. When a rater demonstrated low reliability with other raters for a given participant interaction, that rater's data was removed when computing participants' final [composite] time series; this occurred in approximately $23 \%$ of videos. 
When multiple raters demonstrated poor reliability for a given participant's interaction, we reviewed the video together in bi-weekly team meetings, and raters then re-coded the interaction.

\section{Statistical Analyses}

We computed descriptive and correlational statistics for CAID parameters (Table 2) as a first step in analyzing data. For average warmth or dominance, we calculated the mean of all wives' or husbands' warmth or dominance within each situation and overall. For a domain's variability, we calculated all wives' or husbands' standard deviations within each situation and overall. Each spouse's shape was calculated as a correlation between their warmth and dominance residual time series data across all situations and for individual situations.

To explain the complementarity coefficients, we must first describe the types of complementarity we calculated for each domain. Dominance complementarity occurs when one individual is submissive while the other is reciprocally dominant. To calculate dominance complementarity at the mean-level we first had to calculate one individual's exact complement averaged across the entire interaction. For example, if the wife's score was 300 on average, the husband would need to be at -300 to have maximum mean-level complementarity. If the husband was actually at -600 , the absolute difference between -300 and -600 , or 300 , would be the deviation from maximal mean-level dominance complementarity. The closer this value is to zero, the closer to maximum meanlevel dominance complementarity. In contrast to mean-level complementarity, moment-to-moment dominance complementarity occurs when the individuals move reciprocally in dominance at the same time while the interaction unfolds (see also Sadler et al., 2011). To calculate moment-to-moment dominance complementarity, we first regress time out of each individual's data, and then correlate the detrended time series between the two individuals. Since dominance scores should be concurrently shifting in opposite directions to be complementary, the closer the correlation is to -1 , the more the dyad is achieving maximum moment-to-moment dominance complementarity. 
Mean-level warmth complementarity occurs when individuals in the dyad are similar in warmth on average. Moment-to-moment warmth complementarity occurs when each individual adjusts their warmth in the same direction from one moment to the next. As such, higher mean-level warmth complementarity is indicated by a smaller absolute difference between the dyad's individual warmth ratings (see Table 1). In contrast to mean-level dominance complementarity, a larger positive correlation between the two individual's detrended data would indicate more moment-to-moment warmth complementarity because both individuals shift in warmth in the same direction from one moment to the next. After calculating descriptive statistics for our parameters, we continued with our Generalizability Theory analyses.

Generalizability Theory analyses are typically conducted in two steps, which correspond with our primary study aims. In the G study, we examined the extent to which observed individual variables varied as a function of person, person sex (husband or wife), couple, situation, rater, and each of their relevant interactions (e.g., person by situation). Factors for dyadic variables included couple, situation, rater, and their interactions. All sources were treated as random effects. Raw G study coefficients vary in size across models due to differences in how each parameter is computed; thus, we present the percentage of total variance accounted for within each model on a common metric. However, the raw variance coefficient can be found in the R scripts provided on the Open Science Framework (OSF) at the following link: https://osf.io/5dh9r/?view_only=60e0fff4cf21477ebc597b72a64d843f. We performed these analyses in R using the Ime4 package (Bates et al., 2015).

In the D study, which corresponds to our second study aim, we assessed distinct forms of between-person reliability and the within-person reliability of change across situations (Brennen, 2001; Cronbach \& Shavelson, 2004; Shavelson et al., 1989; Cranford et al., 2006). We adopted Cranford and colleagues (2006) description of four D study coefficients. These reliability estimates are similar to familiar inter-rater reliability coefficients such as intra-class correlations. The first coefficient represents 
an estimate of the reliability of ratings within a single fixed situation $\left(R_{1 F}\right)$. This coefficient informs questions like "across all raters, how reliable would a CAID result be for a parameter estimate when obtained from one particular situation?".

$$
\mathrm{R}_{1 \mathrm{~F}}=\frac{\sigma^{2}{ }_{\text {PERSON }}+\left(\sigma^{2}{ }_{\text {PERSON * RATER } / 4}\right)}{\sigma_{\text {PERSON }}^{2}+\left(\sigma_{\text {PERSON }}^{2} \text { RATER } / 4_{4}\right)+\left(\sigma^{2}{ }_{\text {ERROR } / 4}\right)}
$$

Note: This is calculated for each parameter of interest as described in Table 4. To calculate this coefficient for a dyad, we replace each of the $\sigma^{2}$ PERSON with $\sigma^{2}$ DYAD.

The second coefficient estimates the reliability of ratings aggregated across all raters and situations $\left(\mathrm{R}_{\mathrm{kF}}\right)$. This coefficient can be used to answer questions like "across all raters, how reliable would a CAID result be for a parameter estimate if it was derived from all four of the situations?".

$$
\mathrm{R}_{\mathrm{KF}}=\frac{\sigma_{\text {PERSON }}^{2}+\left(\sigma_{\text {PERSON }}^{2} \text { RATER } / 10\right)^{2}}{\sigma_{\text {PERSON }}^{2}+\left(\sigma_{\text {PERSON }}^{2} \text { RATER } / 10^{2}\right)+\left(\sigma^{2} \text { ERROR } / 4 * 10\right)}
$$

Note: This is calculated for each parameter of interest as described in Table 4. To calculate this coefficient for a dyad, we replace each of the $\sigma^{2}$ PERSON with $\sigma^{2}$ DYAD.

The third coefficient estimates the extent to which behavioral observations obtained from one random situation reliably relate to behaviors during different situations $\left(R_{1 R}\right)$. This coefficient assesses the reliability of CAID parameters in a situation in which each person was measured in a randomized situation, and thus answers questions like "how reliable would a CAID result be for a parameter estimate if it was derived from any of the situations (randomized across participants)?".

$$
\mathrm{R}_{1 \mathrm{R}}=\frac{\sigma_{\text {PERSON }}^{2}+\left(\sigma_{\text {PERSON }}^{2} \text { RATER } / 4\right)}{\sigma_{\text {PERSON }}^{2}+\left(\sigma_{\text {PERSON }}^{2} \text { RATER } / 4\right)+\sigma_{\text {SITUATION }}^{2}+\sigma^{2} \text { SITUATION * RATER }+\left(\sigma_{\text {ERROR } / 4)}^{2}\right)}
$$

Note: This is calculated for each parameter of interest as described in Table 4. To calculate this coefficient for a dyad, we replace each of the $\sigma^{2}$ PERSON with $\sigma^{2}$ DYAD.

The fourth coefficient $\left(R_{c}\right)$ estimates the degree to which the within-person changes across situations are due to true changes in behaviors relative to measurement unreliability. This coefficient helps answer questions like "how reliably can CAID rate within-person change for a parameter estimate from one situation to the next?". 


$$
\mathrm{R}_{\mathrm{C}}=\frac{\sigma_{\text {PERSON * SITUATION }}^{2}}{\sigma^{2}{ }_{\text {PERSON }} \text { *SITUATION }+\left(\sigma_{\text {ERROR/10 })}^{2}\right.}
$$

Note: This is calculated for each parameter of interest as described in Table 4. To calculate this coefficient for a dyad, we replaced each of the $\sigma^{2}$ PERSON with $\sigma^{2}$ DYAD.

We modeled the number of raters as 10 , the total number who contributed data, for all D study analyses except when estimating the reliability of raters within the same situation $\left(R_{1 F} \& R_{1 R}\right)$, in which we modeled the number of raters as 4 , the number who rated a given situation. When calculating reliability coefficients, we treated situations and CAID parameters as fixed and all person and interactions with persons as random. This allowed us to assess how reliable these parameters in CAID assessments would be for randomly sampled persons during a fixed situation. We performed these analyses in R using the Ime4 package (Bates et al., 2015). The raw and transformed data files and R scripts we used for all analyses and graphs in this study are available through OSF (https://osf.io/5dh9r/?view_only=60e0fff4cf21477ebc597b72a64d843f).

\section{Results}

\section{Descriptive Statistics}

We computed descriptive and correlational statistics for CAID indices (Table 2) as a first step in analyzing data. On average, people tended to behave in a slightly warm and dominant manner, suggesting that the absolute midpoint of CAID warmth and dominance scales do not reflect the average level of warmth and dominance in dyadic interactions (see also Hopwood et al., 2020). The withinperson shape of warmth and dominance was close to zero on average, consistent with a large body of research which has found these dimensions to be orthogonal across people (e.g., Fournier et al., 2010). There was appreciable variability in both spouse's warmth and dominance across all situations and overall, meaning that most people tend to fluctuate in both warmth and dominance throughout an interaction. On average, variabilities in spouses' behaviors were highly correlated for both dimensions. 
This suggests that as one spouse varied more in their warmth or dominance, the other spouse would also vary more during a given situation.

We observed a range of mean-level and moment-to-moment complementarity coefficients across dyads for both IPC dimensions. Dominance complementarity occurs when one individual is submissive while the other is dominant and vice versa. Maximum mean-level dominance complementarity occurs when a spouse's average dominance from an interaction approximates the reciprocal of the other spouse's dominance. With these couples, mean-level dominance hovered around $140(95 \% \mathrm{Cl}=130-149)$, meaning that they deviated about 140 from maximal mean-level complementarity in each situation. On average both people tend to be more dominant than the midpoint of the scale, rather than one being dominant and the other being submissive. Moment-tomoment dominance complementarity occurs when the couple reciprocate fluctuations in dominance throughout the discussion (e.g. as one person becomes more dominant, the other becomes more submissive). This is calculated as a correlation between the spouse's residual time series data. On average, dyads displayed strong momentary complementarity in dominance across all situations, averaging around $-.54(95 \% \mathrm{Cl}=-.52--.57)$.

An interesting question was whether or not couples that displayed more mean-level complementarity would also show higher levels of moment-to-moment complementarity. Given that values closer to zero suggest more mean-level complementarity and smaller coefficients suggest more moment-to-moment complementarity for dominance, a higher positive correlation between these two coefficients would indicate that dyads with higher mean-level complementarity also have higher dominance complementarity from one moment to the next. Our results indicate significant positive correlations in wife conflict $(.24,95 \% \mathrm{Cl}=.07-.39)$, husband conflict $(.29,95 \% \mathrm{Cl}=.13-.44)$, and best things situations $(.44,95 \% \mathrm{Cl}=.30-.57)$ and overall with an average of $.30(95 \% \mathrm{Cl}=.22-.38)$, indicating 
that couples do tend to show more moment-to-moment dominance complementarity when they have more mean-level complementarity.

Warmth complementarity occurs when both individuals are similarly warm or cold during an interaction on average (i.e., mean-level complementarity) or shift in the same direction from one moment to the next (i.e., moment-to-moment complementarity). Mean-level complementarity estimates were under $\sim 100$ across all situations $(95 \% \mathrm{Cl}=69-83)$, with some dyads' showing more similar levels of warmth or coldness, on average. Regarding moment-to-moment warmth complementarity, our observations indicate moderate complementarity across all situations with an average correlation of $.38(95 \% \mathrm{Cl}=.36-.40)$.

Given that values closer to zero indicate more mean-level warmth and higher coefficients indicate more moment-to-moment complementarity, a more negative correlation between these estimates would suggest that dyads with more mean-level complementarity also have more warmth complementarity from one moment to the next. Across all situations, warmth complementarity correlations between mean-level and moment-to-moment were negative, but only significant in the husband conflict $(-.36,95 \% \mathrm{Cl}=-.21-[-.50])$ and best things situations $(-.25,95 \% \mathrm{Cl}=-.08-[.40])$, as well as, overall $(-.20,95 \% \mathrm{Cl}=-.12-[-.28])$. Overall, both dominance and warmth complementarity correlations suggest that couples who trend towards mean-level complementarity also have higher moment-to-moment complementarity, yet these forms of complementarity are nevertheless distinct from each other.

\section{G Study Results}

The first goal of our study was to assess the relative influence of characteristics related to persons, partners, situations, raters, and their interactions on interpersonal behaviors. We evaluated this using Generalizability Theory and provide our $\mathrm{G}$ study results in Table 3. Each column represents a CAID parameter, whereas each row represents a potential source of influence on variance in CAID 
parameters. There are no standard guidelines for determining what values constitute sizeable sources of influence on different parameters across unique studies with varying metrics. The common approach to discussing these estimates in G study analyses is to report and evaluate each source's absolute and relative influence on each parameter (Briesch et al., 2014). Each value is represented as a percentage of its influence on each parameter (raw coefficients for each parameter are available at https://osf.io/5dh9r/?view_only=60e0fff4cf21477ebc597b72a64d843f). Significance testing for random effects is computationally complex and can result in inaccurate $p$-values when variance estimates are close to zero. Therefore, we used a combination of Likelihood Ratio Tests (LRT) and the value's absolute size to determine the significance of variance estimates (Luke, 2017). Using LRT's, we found that estimates under $9 \%$ yielded inconsistent $p$-values that clustered around $.01-.05$ when compared to the relative size of the estimate. For this reason, we report all LRT-determined significance, but we constrain our own interpretations of significance to values greater than $9 \%$. Additionally, we determined values exceeding $25 \%$ as the most significant contributors, and we have the most confidence that estimates above this threshold would replicate.

\section{Between-person levels of warmth and dominance}

A general pattern in these findings was that each parameter was influenced by multiple systematic sources, although residual error also accounted for between $19-68 \%$ of the variance in CAID ratings. Individual differences in couples was the primary influence on average levels of warmth (25.1\%), followed by a combination of significant individual differences in people (10.6\%), situations (9.6\%), and the couple $x$ situation (12.1\%) and couple $x$ rater interactions (9.7\%); other sources had minimal impact. In contrast, the strongest influence on average levels of dominance was individual differences in people (42.8\%), followed by a significant person $x$ situation interaction (24.1\%). This pattern suggests that warmth is a characteristic of couples to a greater degree than dominance, which is more a characteristic 
of individuals. Situational variance (as a main effect or via interactions) was a weaker, albeit meaningful, factor for both (See Table 3 for more details).

\section{Variabilities and within-person correlations of warmth and dominance}

The factors that influenced variability in warmth and dominance were fairly similar. Raters were the most prominent and significant factor for both of these variables (warmth $=17.8 \%$, dominance $=$ $24.0 \%)$, suggesting that some raters reliably tended to move the joystick more than others as they were coding interactions. The significant couple by situation interaction for both parameters suggested that some couples were more activated by different situations whereas others had more consistent patterns across situations (warmth $=12.8 \%$, dominance $=11.5 \%$ ). Significant interactions between raters and couples for both warmth (10.7\%) and dominance (11.0\%), as well as raters and situations for dominance (9.6\%), suggested that some raters were more sensitive to variation in interpersonal behavior across different interactions than others. Whereas individual differences in couples (13.2\%), but not situations, significantly influenced warmth variability, these two factors were only slightly impactful on dominance variability. Shape was primarily, and most significantly, a function of the person $\mathrm{x}$ situation interaction (24.7\%), suggesting that some people tend to conflate warmth and dominance in certain situations more than others.

\section{Complementarity}

Both couples (22.3\%) and the couple by situation interaction (21.5\%) had strong and significant influences on mean-level warmth complementarity, indicating that some couples tend to be more congruous in their warmth than other couples, and some show more warmth congruity in certain situations than in others. The couple $x$ situation interaction (15.7\%) also significantly influenced moment-to-moment warmth complementarity, suggesting that some couples show consistently more warmth complementary during some situations. 
Both raters (18.3\%) and the couple by situation interaction (17.6\%) comparably and significantly influenced mean-level dominance complementarity. This suggested that some raters maintained their ratings of individuals in certain dyads as opposites in dominance, while rating other couples as more similar in dominance, on average. The couple by situation interaction indicated that a number of couples were more successful at sharing power in certain conversations compared to others, on average. While couple variation (9.4\%), though significant, had limited influence at the mean-level, it had the largest significant influence on moment-to-moment complementarity (24.3\%), meaning some couples balanced power more consistently throughout an interaction than others. Momentary dominance complementarity was also significantly influenced by couple $\mathrm{x}$ situation interactions (19.3\%), as some couples showed more momentary dominance reciprocity in certain situations in comparison to other situations. A significant yet modest amount of variance in these ratings was due to unique rater effects (11.8\%), indicating that some raters consistently observed more momentary dominance reciprocity than other raters.

\section{Study Results}

As stated above, in the D study we assessed distinct forms of between-person reliability and within-person reliability of change across situations using the variance scores from the G study. Throughout this section we refer to the reliability coefficients in Table 4 and evaluate these with regard to the $\mathrm{G}$ study variance estimates in Table 3. Cut-offs for reliability estimates vary greatly across different studies; many are determined based on the design of the study and how the measure is being used (Briesch et al., 2014). We interpreted reliabilities less than .40 as poor, between .41 and .59 as fair, between .60 and .74 as good, and values between .75 and 1.0 as excellent; following commonly cited cut-offs for intraclass correlations for observational data (Cicchetti, 1994; Hallgren, 2012).

\section{Between-person levels of warmth and dominance}


Consistent with prior CAID research, our estimates of the between-person reliability of average ratings taken from the same situation $\left(R_{1 F}\right)$ suggest that raters provided good estimates of mean warmth (.69) within a given situation, although dominance estimates were even more reliable (.90). When ratings were aggregated across all raters and situations $\left(R_{\mathrm{KF}}\right)$ estimates of reliability for a person's typical warmth (.96) and dominance (.99) were excellent. Examining behaviors across different situations $\left(R_{1 R}\right)$, our results suggest that single assessments of dominance provided reliable estimates of a person's general tendency to be dominant (.84). Single assessments of average warmth, or a person's general tendency to be warm, yielded poor estimates of reliability (.37). Lastly, our results indicated that changes in average ratings across situations (that is, true within-person change; $R_{c}$ ) in dominance (.92) and in warmth (.75) had excellent reliability, across differing situations. Overall, this pattern of results indicates that estimates of how warm or dominant a person will tend to be, relative to others, can be estimated fairly reliably from a single interaction using CAID, with the exception that an individual's warmth in one situation does not necessarily extend to their likelihood to be warm, in general.

\section{Variabilities and within-person correlations of warmth and dominance}

CAID scores averaged across all raters for a single situation provided fairly reliable estimates in warmth variability (.41), but estimates for dominance variability had poor reliability (.25). When averaged across all situations, variability estimates for warmth (.87) and dominance (.77) had excellent reliability. Our estimates for true within-person changes in warmth variability (.36), as well as, our ability to accurately estimate a person's general warmth variability with a random situation (.22) yielded poor reliability estimates. For dominance variability, estimates of true within-person changes were fairly reliable (.57), while those for estimating a person's general dominance variability in a random situation showed poor reliability (.08).

Both estimates of interpersonal shape for a single fixed situation and a single random situation showed poor reliability across raters $\left(R_{1 F}=.30, R_{1 R}=.18\right.$; respectively). These results are not surprising 
given that shape is highly influenced by the interaction between person and situation characteristics (see Table 3), which suggests that a person may harmonize their warmth and dominance behaviors more or less depending on the situation. In line with this interpretation, summary scores of shape aggregated across situations for the typical patterning of a person's interpersonal behaviors (.79) and true within-person changes in shape (.84) had excellent reliability. Similar to variability, CAID scores for shape are more reliable when assessed across multiple situations as a person's interpersonal shape may change idiosyncratically across distinct situations.

\section{Complementarity}

The reliability of mean-level complementarity across raters within a single situation was good for warmth (.70) and fair for dominance (.48). In contrast, for moment-to-moment assessments of complementarity, the reliability across raters within each discussion in estimating dominance was excellent (.76), but poor for warmth (.26), perhaps owing to the considerable error variance in our assessment of moment-to-moment warmth complementarity. As with indices of individual behavior, estimates of mean-level complementarity for warmth (.96) and dominance (.90), and moment-tomoment warmth (.78) and dominance (.97), had excellent reliability when aggregated across all raters and situations. In contrast, estimates for a couple's general mean-level dominance complementarity from a single situation had poor reliability (.37). However, estimates of mean-level warmth complementarity from a single interaction as an indicator of a couple's tendency to show mean-level complementary during other interactions had good reliability (.64). Estimates from a single situation for a couple's general tendency to show moment-to-moment complementarity had good reliability regarding dominance (.60), yet poor reliability for warmth (.22); again, likely due to the relatively high error variance in moment-to-moment warmth. Lastly, estimates of true changes in dyadic behaviors across distinct discussions for both mean-level warmth (.84) and dominance complementarity (.80), as well as, moment-to-moment warmth (.70) and dominance complementarity (.86) yielded excellent 
reliability. This indicates that changes in CAID ratings of complementarity are truly changes in the dyad's complementarity and not due to measurement artifacts. Overall, these results suggest that many CAID parameters can be interpreted reliably based on data from a single interaction, although all of them yield reliable estimates that are improved with assessments of additional situations.

\section{Discussion}

The goal of this study was to use Generalizability Theory methods to decompose the variance in observer coded ratings of interpersonal behavior in a sample of couples who interacted in four different tasks. Overall, data support the use of the Continuous Assessment of Interpersonal Dynamics (CAID) for measuring within-situation interpersonal dynamics. There were three main results. First, multiple systematic sources of variance influenced the data, suggesting that CAID can be used to make a variety of inferences about interpersonal dynamics. Second, different CAID parameters were influenced by different factors, suggesting the importance of considering a range of features in trying to unpack complex interpersonal interactions. Third, reliabilities for different kinds of CAID-based inferences varied, which revealed the utility of assessing interpersonal behaviors across multiple situations. This suggests that CAID data from a single interaction is sufficient for making certain interpretations, whereas in other cases, more data is needed to ensure reliable conclusions.

\section{Between-person levels and variabilities of warmth and dominance}

Each of the parameters estimated by CAID communicates different kinds of information about the person and dyad being assessed. Average warmth and dominance convey how warm or dominant a person was in a certain situation, on average. When averaged across multiple interactions, this parameter can be used to indicate a person's general demeanor in social situations, relative to others. By and large, participants tended to be warm and dominant across all situations, in an absolute sense (i.e., average CAID values were positive). Moreover, levels of warmth were positively correlated between spouses, whereas levels of dominance had strong negative correlations between spouses. 
These effects are generally consistent with the interpersonal principle of complementarity, as aggregated across an entire interaction.

We decomposed the variance in warmth and dominance levels using Generalizability Theory. We found that couple characteristics and their interaction with situations significantly influenced average warmth, whereas person characteristics and their interaction with situations heavily impacted average dominance. Warmth findings suggest the possibility of assortative mating effects as well as the power of the situation to impact the emotional tenor and interpersonal closeness characteristics of a single interaction. In contrast, these results imply that dominance tends to behave more like a trait that is relatively stable across situations. The relative influence of person and situation factors on behaviors is a longstanding debate in psychology (Donnellan et al., 2009; Epstein \& O'Brien, 1985; Hogan, 2009; Kenrick \& Funder, 1988; Moskowitz et al., 1994; Funder \& Dobroth, 1987; John \& Robins, 1993), and our data suggest that the magnitude of these influences may depend on the dimension or trait being considered. These results specifically support dominance as more of a personal characteristic in comparison to warmth, although both are subject to the influence of both traits and situations.

A unique advantage of CAID, relative to event-contingent ambulatory approaches that attempt to account for an entire interaction with a single summary, is the capacity to capture variability around average levels of behavior or psychological experience within an interaction. Significant variability was observed in both warmth and dominance as interactions unfolded. Variability in both domains was positively correlated between couples across all situations. This suggests that as one spouse changed in a domain of behavior, so did the other in the same direction. For example, if one individual was slightly cold and started to warm up while talking about the best things in their relationship, the other individual would also get warmer regardless of their warmth prior to their spouse's adjustment. Generalizability Theory results indicated that differences in rater perception had a significant impact on fluctuations in these domains, especially dominance variability. This finding suggests that some raters reliably move the 
joystick device more often than others, and this represents systematic (non-error) variation that is independent of the actual interpersonal process being coded.

\section{Within-person correlations of warmth and dominance}

Because it can account for variability as a situation unfolds, CAID allows for tests of the synchrony between individuals' warmth and dominance within interactions. In other words, we can correlate these behaviors within people to assess whether a person's warmth is connected to or dependent on their dominance during an interaction, which is sometimes referred to as shape (Fournier et al., 2008). Both warmth and dominance domains are tracked across time within an interaction, so a correlation between these would indicate if and to what extent an individual's shifts in dominant and submissive behaviors coincide with shifts in their warm and cold behaviors. Examples of within-person questions would be: Is this person often cold when they are assertive? Or are they cold when they become more passive? The interaction between person and situation characteristics had the largest impact on shape's variance in this study, indicating that some people's warmth and dominance tended to be synchronized more in some situations than others, to a greater degree than was the case for other people. For example, some people might tend to vacillate between acting friendly/assertive and aloof/passive while planning a vacation with their spouse, whereas their assertiveness may be unrelated to their warmth while discussing the best things in their relationship.

Although warmth and dominance are orthogonal, on average and across people, our results suggest that they are correlated among certain individuals, particularly in certain situations. The standard deviations in shape suggest wide-ranging variability in shapes across people, supporting the distinction between orthogonality of the interpersonal circumplex dimensions on average and the possibility that they may become intertwined under certain circumstances. This could have important clinical implications. For instance, a patient who habitually treats others coldly when they are in positions of authority may be disliked, and their authority undermined by their own tactless behavior. 
Helping such patients distinguish dominance from warmth, and perhaps practicing behaving in a way that is assertive but not cold, may be a useful and targeted intervention.

\section{Complementarity}

Complementarity refers to the general principle that dominance begets submission and warmth begets warmth (Carson, 1969; Kiesler, 1996; Sadler et al., 2011). Complementary describes relationship dynamics at work (Moskowitz et al., 2007; Chen \& Bernstein, 2000), in therapy (Altenstein et al., 2013; Hopwood et al., 2016; Pincus et al., 2014, 2019; Thomas et al., 2014; Ramseyer \& Tschacher, 2014), among peers (Ansell et al., 2008), roommates (Markey \& Kurtz, 2006), and in educational settings (Bernieri, 1988; Pennings et al., 2014; Thijs et al., 2011).

However, this pattern could occur at different time scales, and these different time scales can, in turn, influence complementarity estimates (Tracey, 2004). We computed both moment-to-moment and mean-level complementarity. Moment-to-moment complementarity reflects the degree to which changes in one person's behavior are associated with changes in the other person's behavior, in real time. Mean-level complementarity refers to the similarity of scores, aggregated across the entire interaction.

Consistent with theory and previous research, we found robust evidence for complementarity at both of these levels. Momentary complementarity was somewhat higher for dominance than warmth, whereas mean-level complementarity was somewhat higher for warmth than for dominance. This suggests a relatively stronger tendency for people to behave reciprocally in terms of dominance than to behave similarly on warmth while a situation unfolds. In contrast, both parties will tend to match in their overall level of warmth during an interaction to a greater degree than they will settle into high and low dominance positions. Moreover, these two operationalizations of complementarity were correlated with one another, although this effect was far from unity. This pattern of findings suggests that there is 
considerable nuance to the concept of complementarity, and in particular that the dynamic may have different properties at different time scales (Tracey, 2004; Sadler et al., 2011).

Because complementarity is a dyadic variable, variation in complementarity estimates could only be impacted by dyadic, situational, or rater variables. In general, the strongest impacts across both kinds of complementarity, for both dominance and warmth, was the interaction between couple and situation. This suggests that the interaction pattern is affected by the situation more for some couples than others. For example, some couples may be better at sharing dominant roles in non-conflict situations but complementarity tends to break down in conflict situations, whereas other couples are able to maintain complementarity across situations. The main effect of couple characteristics was strongest for mean-level warmth complementarity and momentary dominance complementarity. Momentary dominance complementarity was also significantly impacted by rater effects, which was the strongest influence on mean-level dominance complementarity. Some raters may perceive dominant and submissive complementary behaviors more than other raters, as discussed in more detail below. However, raters had less of an effect on warmth complementarity. We note that the variation around warmth was relatively small. This lack of variation may have contributed to the considerable amount of measurement error in momentary warmth complementarity. This is likely due to the relative lack of reliable variation in warm behaviors throughout interactions; in these data most people were warm most of the time (Table 2).

\section{The reliability of CAID data}

Generalizability Theory provides an opportunity to examine the degree to which different kinds of inferences can be reliably made about individuals and dyads via "D study" analyses. In this study, we distinguished four types of inferences, each with its own reliability estimate for different parameters. As discussed in Results section, we followed frequently cited cut-offs for intraclass correlations with 
observational data (Cicchetti, 1994; Hallgren, 2012) and described reliabilities less than .40 as poor, between .41 and .59 as fair, between .60 and .74 as good, and values between .75 and 1.0 as excellent.

The first coefficient we calculated estimated the reliability of CAID scores within one specific situation assessed by 4 raters $\left(R_{1 F}\right)$. Reliability estimates were in the good range for average dominance and warmth, as well as moment-to-moment dominance and mean-level warmth complementarity. In other words, given a single situation, 4 raters' assessments of a couple's average interpersonal behaviors and some of their complementary behaviors provided relatively accurate representations of these behaviors for that particular type of situation (e.g., planning a vacation). Warmth variability and mean-level dominance were estimated fairly reliably within a single situation. Both rater effects and situational interactions influenced warmth variability and mean-level dominance, which could explain the relatively lower reliability estimates (i.e., these estimates could change with different raters or different situations). Therefore, including either more raters or more situations would likely result in higher levels of reliability. Lower estimates were observed for dominance variability, shape, and moment-to-moment warmth complementarity when assessed in only one situation. It is possible that the significant impact of rater effects on dominance variability and shape led to poor reliability in these estimates. One way to combat this effect is by having more raters and situations, which could increase reliability in these estimates. Moment-to-moment warmth complementarity was particularly prone to measurement error, likely because there was a lack of variation in warmth; without reliable variance, unreliable variance can muddy the results.

The second estimate was used to determine if CAID could reliably estimate the same parameters across all raters and all four situations $\left(R_{\mathrm{KF}}\right)$. This answers questions like, "When aggregated, do assessments of an individual's or couple's behavior from all 10 raters across all 4 situations yield reliable estimates of those behaviors for those types of situations?" We found that all CAID parameters had excellent reliability across all raters and situations. This indicates that a pretty reliable portrait of 
interpersonal dynamics can be obtained by having multiple raters code people with CAID in four different interactions. Given that all interactions were within couple dyads, it remains an open question how well such parameters might generalize to the same individuals, in other dyads (e.g., the same people interacting with co-workers or children).

The third reliability estimate is similar to the first in that it only takes one interaction into account. However, unlike the first estimate, which focused on the generalization of CAID data to other, similar interactions (e.g., generalizations to similar discussions about planning vacations), the third estimate $\left(R_{1 R}\right)$ tests the ability to generalize CAID data from one interaction to the person's behavior, in general (e.g., generalizations to discussions about vacations and conflicts). This value is naturally always lower than the first estimate, described above $\left(R_{1 F}\right)$. We found excellent reliability in estimates of average dominance, as well as good reliability in estimates of moment-to-moment dominance complementarity and mean-level warmth complementarity. This suggests that for average dominance, moment-to-moment dominance complementarity, and mean-level warmth complementarity, a single situation assessed by 4 raters is sufficient to provide reasonably accurate estimates of a person's or couple's general behaviors within these parameters in most situations and relative to other people. In contrast, we observed poor reliability estimates of average warmth, variability, shape, mean-level dominance complementarity, and moment-to-moment warmth complementarity; all of which were considerably influenced by multiple factors, including rater effects and situational interactions. By and large, CAID provides more reliable estimates of interpersonal behaviors when aggregated across more raters and multiple situations, but a single situation does produce some reliable estimates of people's general behaviors.

Lastly, the within-person reliability of change across situations indicates whether CAID parameters are sensitive to behavioral changes in different interactions $\left(R_{c}\right)$. These values were relatively high across the board, with the exception of warmth and dominance variability; meaning that 
changes in people's behaviors for many of the parameters were real variations in their behaviors and not a methodological artefact of CAID. Lower estimates for variability may be due to rater effects, in which some raters may have perceived different patterns of change, clouding the true within person fluctuations. The sensitivity to situational dynamics reflected in these findings point to the value of using CAID to examine contextual influences on interpersonal behavior.

Generally, CAID parameters are most reliable when assessed in multiple situations by multiple raters. Although estimates are less reliable in single assessments, valuable information about a person's warmth and dominance can still be observed using CAID. Future researchers should consider how using single or multiple assessments may impact the generalizability of their findings. The reliability estimates provided in this study should aid in evaluating the appropriate circumstances for which to use CAID.

\section{Limitations and Future Directions}

Our results demonstrate CAID's value in providing fine-grained information about how interpersonal interactions unfold over time. Given the potential of CAID for research and applied assessment, these results provide critical information that can be used to support the use of this rich

measurement approach. Nevertheless, several design limitations constrain the generalizability of these results.

Although we studied a relatively large sample of couples drawn from a diverse community, because of broader study goals we only collected data from opposite sex couples with young children. Future research should attempt to replicate and extend these findings to other populations, such as same-sex couples, newly formed relationships (Markey et al., 2010), parent-child (Klahr et al., 2013), or co-worker dyads (Moskowitz et al., 2007; Chen \& Bernstein, 2000), particularly given the potential value of CAID for illuminating interpersonal dynamics in such populations.

Raters represented a significant systematic source of variance in multiple CAID parameters, particularly variability and some forms of complementarity. While rater variance can be considered a 
source of systematic error in assessed behaviors, this finding also illuminates a potentially useful application of the CAID method as a perceptual task, in which variation in rater behavior becomes the focus. For instance, participants or patients could code a common, standardized interaction using CAID, and the deviation of their codes from some standard could be used to make inferences about how they perceive interactions. There may also be some value in pursuing this line of work to aid in selecting and training raters, in order to improve the standardization and consistency of the CAID approach.

When assessing moment-to-moment complementarity, we did not evaluate time-lagged relations when computing correlations. Some authors have suggested that complementarity implies a lead-lag relationship between the output of one person and the reaction from the other. However, studies assessing time-series associations in interactions have not found consistent lead-lag relations and instead have found primarily simultaneous effects (Cappella, 1996). Possible explanations for this simultaneous effect in time-series associations are that partners may be anticipating behaviors and responding concurrently or that lagged processes happen too quickly to perceive (Sadler et al., 2009). It is also possible that actual lead-lag processes are present in some dyads, at different timescales, or during only some segments of particular interaction, that are lost in aggregation. Future research should explore the presence and relevance of lagged associations that might not generalize across dyads, situations, or moments.

The main practical barrier to using CAID is that it is very time-intensive to have multiple individuals carefully watch interactions twice. In practical settings (e.g., psychotherapy), it may be impossible to implement CAID coding as a routine element of assessment. In such cases, it might be more fruitful to code certain cases sessions that seem particularly important (see Hopwood et al., 2016), Indeed, CAID coding is a laborious assessment approach even in research settings. Future researchers may wish to vary the number of coders or intensity of training in order to test the impacts on reliability 
and validity. It may be also possible to develop more effective coding strategies; the use of machine learning algorithms to code sessions automatically seems particularly promising.

One general take home message from this study is that the challenges associated with rating warmth are different than the challenges associated with rating behavioral dominance. As mentioned above, warmth tends to vary less in general, and thus there are fewer opportunities to reliably capture shifts in warmth than in dominance, and this likely contributes to the somewhat lower reliability of momentary complementarity on warmth. Some dominance displays may also be more visible. For instance, speaking is typically (but not always) more dominant than not speaking, and this is a relatively easy cue to code. Finally, these results suggest that different sources drive warmth and dominance levels. Thus, to the degree that raters know something about the situation or the people in it (e.g., how conflictual the interaction is or how dominant the person tends to be), they may be better equipped to code the interaction reliably.

This research raises questions about the place of CAID and other tools designed to capture within-situation dynamics among currently popular EMA methods that are designed to assess dynamics across situations (e.g., Trull \& Ebner-Priemer, 2020; Wright \& Zimmermann, 2019). The most similar type of EMA design is perhaps event-contingent approaches in which participants describe a single interpersonal interaction (Moskowitz et al., 2009). In event-contingent EMA data, individual behaviors and complementarity are calculated using a person's recollection of average behaviors from an interaction, which they can do throughout the day over many interactions with many individuals. In contrast, CAID uses multiple observers' assessments of an individual's moment by moment behaviors and aggregates of those assessments in a specific set of interactions to estimate individual and dyadic patterns of behavior, as the situation unfolds.

Would we make the same inferences about a person's typical level of warmth and dominance using these different measurement approaches? Is complementarity comparable across these 
approaches? We were able to touch upon this issue to a limited degree by examining both mean-level and moment-to-moment complementarity. We found that there was a significant association between these kinds of complementarity. That is, couples who have more momentary reciprocity on warmth also tend to be more similar in warmth overall during the course of an interaction. However, this association was fairly modest, and other research suggests that momentary complementarity is a more valid approximation of the theoretical construct (i.e., one person's behaviors immediately invites specific behavior from another person; Kiesler, 1996; Sadler et al., 2011; Tracey, 2004). This suggests a possible limitation of EMA assessment for observing meaningful shifts in complementary behaviors. That beind said, another difference between CAID and EMA is that EMA studies occur in peoples' everyday environment whereas CAID is typically used to code prompted laboratory interactions (Woods \& Wright, 2019). The laboratory setting affords the researcher more control, but the artificial setting may invoke slight differences in behavior than those in a natural environment. As such, adapting approaches like CAID to capture behavior in more naturalistic environment is an important future direction. Future research should also evaluate, directly and empirically, the degree to which data from existing ambulatory approaches designed to capture between-situation variation align with CAID and other approaches designed to capture within-situation variation.

\section{Conclusion}

In this study we have shown that CAID can isolate multiple sources of variance in multiple clinically relevant interpersonal behaviors observable as interactions unfold, and it can do so reliably and in relatively short periods of time. These results suggest some promise for the use of CAID in both research on interpersonal processes (e.g., in psychopathology or psychotherapy) as well as the potential for the use of CAID in clinical assessment (e.g., Hopwood et al., 2016). Specific results provide prior expectations for researchers wishing to extend these findings. 


\section{References}

Altenstein, D., Krieger, T., \& Grosse Holtforth, M. (2013). Interpersonal microprocesses predict cognitiveemotional processing and the therapeutic alliance in psychotherapy for depression. Journal of Counseling Psychology, 60(3), 445-452. https://doi.org/10.1037/a0032800

Ansell, E. B., Kurtz, J. E., \& Markey, P. M. (2008). Gender Differences in Interpersonal Complementarity Within Roommate Dyads. Personality and Social Psychology Bulletin, 34(4), 502-512. https://doi.org/10.1177/0146167207312312

Assaad, L., Lane, S., Hopwood, C. J., Durbin, C. E., \& Thomas, K. M. (in press). Personality Pathology and Spouses' Moment-to-Moment Interpersonal Behaviors. Journal of Personality Disorders. https://doi.org/10.1521/pedi $201933 \quad 444$

Bates, D., Mächler, M., Bolker, B., \& Walker, S. (2015). Fitting Linear Mixed-Effects Models Using Ime4. Journal of Statistical Software, 67(1). https://doi.org/10.18637/jss.v067.i01

Beal, D. J., \& Weiss, H. M. (2003a). Methods of Ecological Momentary Assessment in Organizational Research. Organizational Research Methods, 6(4), 440-464. https://doi.org/10.1177/1094428103257361

Beal, D. J., \& Weiss, H. M. (2003b). Methods of Ecological Momentary Assessment in Organizational Research. Organizational Research Methods, 6(4), 440-464. https://doi.org/10.1177/1094428103257361

Bernieri, F. J. (1988). Coordinated movement and rapport in teacher-student interactions. Journal of Nonverbal Behavior, 12(2), 120-138. https://doi.org/10.1007/BF00986930

Boon-Falleur, M., Bouguen, A., Charpentier, A., Algan, Y., Huillery, E., \& Chevallier, C. (2020). Measuring socioemotional skills in schools: Simple questionnaires outperform behavioral tasks [Preprint]. PsyArXiv. https://doi.org/10.31234/osf.io/w7pr6

Brennan, R. L. (2005). Generalizability Theory. Educational Measurement: Issues and Practice, 11(4), 27-34. https://doi.org/10.1111/j.1745-3992.1992.tb00260.x 
Briesch, A. M., Swaminathan, H., Welsh, M., \& Chafouleas, S. M. (2014). Generalizability theory: A practical guide to study design, implementation, and interpretation. Journal of School Psychology, 52(1), 13-35. https://doi.org/10.1016/j.jsp.2013.11.008

Cappella, J. N. (1996). Dynamic coordination of vocal and kinesic behavior in dyadic interaction: Methods, problems, and interpersonal outcomes. In Dynamic patterns in communication processes. (pp. 353-386). Sage Publications, Inc.

Carson, R. C. (1969). Interaction concepts of personality. (pp. x, 306). Aldine Publishing Co.

Chen, E. C., \& Bernstein, B. L. (2000). Relations of complementarity and supervisory issues to supervisory working alliance: A comparative analysis of two cases. Journal of Counseling Psychology, 47(4), 485-497. https://doi.org/10.1037/0022-0167.47.4.485

Cicchetti, D. V. (1994). Guidelines, criteria, and rules of thumb for evaluating normed and standardized assessment instruments in psychology. Psychological Assessment, 6(4), 284-290. https://doi.org/10.1037/1040-3590.6.4.284

Cooper, L. D., Balsis, S., \& Oltmanns, T. F. (2012). Self- and informant-reported perspectives on symptoms of narcissistic personality disorder. Personality Disorders, 3(2), 140-154. https://doi.org/10.1037/a0026576

Costa, P. T., \& McCrae, R. R. (2008). The Revised NEO Personality Inventory (NEO-PI-R). In The SAGE Handbook of Personality Theory and Assessment: Volume 2-Personality Measurement and Testing (pp. 179-198). SAGE Publications Ltd. https://doi.org/10.4135/9781849200479.n9

Cranford, J. A., Shrout, P. E., lida, M., Rafaeli, E., Yip, T., \& Bolger, N. (2006). A Procedure for Evaluating Sensitivity to Within-Person Change: Can Mood Measures in Diary Studies Detect Change Reliably? Personality and Social Psychology Bulletin, 32(7), 917-929. https://doi.org/10.1177/0146167206287721 Cronbach, L. J., Rajaratnam, N., \& Gleser, G. C. (1963). Theory of generalizability: A liberalization of reliability theory†. British Journal of Statistical Psychology, 16(2), 137-163. https://doi.org/10.1111/j.20448317.1963.tb00206.x 
Cronbach, L. J., \& Shavelson, R. J. (2004). My Current Thoughts on Coefficient Alpha and Successor

Procedures. Educational and Psychological Measurement, 64(3), 391-418.

https://doi.org/10.1177/0013164404266386

Dawood, S., \& Pincus, A. L. (2018). Pathological narcissism and the severity, variability, and instability of depressive symptoms. Personality Disorders: Theory, Research, and Treatment, 9(2), 144-154. https://doi.org/10.1037/per0000239

DeYoung, C. G., \& Krueger, R. F. (2018). A Cybernetic Theory of Psychopathology. Psychological Inquiry, 29(3), 117-138. https://doi.org/10.1080/1047840X.2018.1513680

Donnellan, M. B., Lucas, R. E., \& Fleeson, W. (2009). Introduction to personality and assessment at age 40: Reflections on the legacy of the person-situation debate and the future of person-situation integration. Journal of Research in Personality, 43(2), 117-119. https://doi.org/10.1016/i.jrp.2009.02.010

Ebner-Priemer, U. W., \& Trull, T. J. (2009). Ecological momentary assessment of mood disorders and mood dysregulation. Psychological Assessment, 21(4), 463-475. https://doi.org/10.1037/a0017075

Epstein, S., \& O’Brien, E. J. (1985). The person-situation debate in historical and current perspective. Psychological Bulletin, 98(3), 513-537. https://doi.org/10.1037/0033-2909.98.3.513

Fonagy, P. (2018). Attachment Theory and Psychoanalysis (1st ed.). Routledge. https://doi.org/10.4324/9780429472060

Foster, D. A., Caplan, R. D., \& Howe, G. W. (1997). Representativeness of observed couple interaction: Couples can tell, and it does make a difference. Psychological Assessment, 9(3), 285-294. https://doi.org/10.1037/1040-3590.9.3.285

Fournier, M. A., David, D. S. M., \& Zuroff, D. C. (2012). Origins and Applications of the Interpersonal Circumplex. In L. M. Horowitz \& S. Strack (Eds.), Handbook of Interpersonal Psychology (pp. 57-73). John Wiley \& Sons, Inc. https://doi.org/10.1002/9781118001868.ch4 
Fournier, M. A., Moskowitz, D. S., \& Zuroff, D. C. (2008). Integrating dispositions, signatures, and the interpersonal domain. Journal of Personality and Social Psychology, 94(3), 531-545. https://doi.org/10.1037/0022-3514.94.3.531

Funder, D. C., \& Dobroth, K. M. (1987). Differences between traits: Properties associated with interjudge agreement. Journal of Personality and Social Psychology, 52(2), 409-418. https://doi.org/10.1037/0022$\underline{3514.52 .2 .409}$

Hallgren, K. A. (2012). Computing Inter-Rater Reliability for Observational Data: An Overview and Tutorial. Tutorials in Quantitative Methods for Psychology, 8(1), 23-34. https://doi.org/10.20982/tamp.08.1.p023 Hedge, C., Powell, G., \& Sumner, P. (2018). The reliability paradox: Why robust cognitive tasks do not produce reliable individual differences. Behavior Research Methods, 50(3), 1166-1186. https://doi.org/10.3758/s13428-017-0935-1

Hogan, R. (2009). Much ado about nothing: The person-situation debate. Journal of Research in Personality, 43(2), 249. https://doi.org/10.1016/j.jrp.2009.01.022

Hopwood, C. J., Ansell, E. B., Pincus, A. L., Wright, A. G. C., Lukowitsky, M. R., \& Roche, M. J. (2011). The Circumplex Structure of Interpersonal Sensitivities: Interpersonal Sensitivities Circumplex. Journal of Personality, 79(4), 707-740. https://doi.org/10.1111/i.1467-6494.2011.00696.x

Hopwood, C. J., Harrison, A. L., Amole, M., Girard, J. M., Wright, A. G. C., Thomas, K. M., Sadler, P., Ansell, E. B., Chaplin, T. M., Morey, L. C., Crowley, M. J., Emily Durbin, C., \& Kashy, D. A. (2020). Properties of the Continuous Assessment of Interpersonal Dynamics Across Sex, Level of Familiarity, and Interpersonal Conflict. Assessment, 27(1), 40-56. https://doi.org/10.1177/1073191118798916

Hopwood, C. J., Thomas, K. M., Luo, X., Bernard, N., Lin, Y., \& Levendosky, A. A. (2016). Implementing Dynamic Assessments in Psychotherapy. Assessment, 23(4), 507-517.

https://doi.org/10.1177/1073191116649658 
Hopwood, C. J., \& Waugh, M. H. (Eds.). (2019). Personality Assessment Paradigms and Methods: A Collaborative Reassessment of Madeline G. (1st ed.). Routledge. https://doi.org/10.4324/9781315143620

Horowitz, L. M., Rosenberg, S. E., Baer, B. A., Ureño, G., \& Villaseñor, V. S. (1988). Inventory of interpersonal problems: Psychometric properties and clinical applications. Journal of Consulting and Clinical Psychology, 56(6), 885-892. https://doi.org/10.1037/0022-006X.56.6.885

John, O. P., \& Robins, R. W. (1993). Determinants of Interjudge Agreement on Personality Traits: The Big Five Domains, Observability, Evaluativeness, and the Unique Perspective of the Self. Journal of Personality, 61(4), 521-551. https://doi.org/10.1111/j.1467-6494.1993.tb00781.x

Kenrick, D. T., \& Funder, D. C. (1988). Profiting from controversy: Lessons from the person-situation debate. American Psychologist, 43(1), 23-34. https://doi.org/10.1037/0003-066X.43.1.23

Kiesler, D. J. (1996a). Contemporary interpersonal theory and research: Personality, psychopathology, and psychotherapy. (pp. xviii, 398). John Wiley \& Sons.

Kiesler, D. J. (1996b). From Communications to Interpersonal Theory: A Personal Odyssey. Journal of Personality Assessment, 66(2), 267-282. https://doi.org/10.1207/s15327752jpa6602 6

Klahr, A. M., Thomas, K. M., Hopwood, C. J., Klump, K. L., \& Burt, S. A. (2013). Evocative gene-environment correlation in the mother-child relationship: A twin study of interpersonal processes. Development and Psychopathology, 25(1), 105-118. https://doi.org/10.1017/S0954579412000934

Leary, T. (1957). Interpersonal diagnosis of personality; a functional theory and methodology for personality evaluation. (pp. xv, 518). Ronald Press.

Lipsitz, J. D., \& Markowitz, J. C. (2013). Mechanisms of change in interpersonal therapy (IPT). Clinical Psychology Review, 33(8), 1134-1147. https://doi.org/10.1016/i.cpr.2013.09.002 
Lizdek, I., Sadler, P., Woody, E., Ethier, N., \& Malet, G. (2012). Capturing the Stream of Behavior: A ComputerJoystick Method for Coding Interpersonal Behavior Continuously Over Time. Social Science Computer Review, 30(4), 513-521. https://doi.org/10.1177/0894439312436487

Lizdek, I., Woody, E., Sadler, P., \& Rehman, U. S. (2016). How do depressive symptoms in husbands and wives relate to the interpersonal dynamics of marital interactions? Journal of Counseling Psychology, 63(6), 721-735. https://doi.org/10.1037/cou0000167

Locke, K. D. (2011). Circumplex measures of interpersonal constructs. In Handbook of interpersonal psychology: Theory, research, assessment, and therapeutic interventions. (pp. 313-324). John Wiley \& Sons, Inc.

Lorenzo-Luaces, L., German, R. E., \& DeRubeis, R. J. (2015). It's complicated: The relation between cognitive change procedures, cognitive change, and symptom change in cognitive therapy for depression. Clinical Psychology Review, 41, 3-15. https://doi.org/10.1016/i.cpr.2014.12.003

Luke, S. G. (2017). Evaluating significance in linear mixed-effects models in R. Behavior Research Methods, 49(4), 1494-1502. https://doi.org/10.3758/s13428-016-0809-y

Markey, P., Lowmaster, S., \& Eichler, W. (2010). A real-time assessment of interpersonal complementarity. Personal Relationships, 17(1), 13-25. https://doi.org/10.1111/i.1475-6811.2010.01249.x

Markey, P. M., \& Kurtz, J. E. (2006). Increasing Acquaintanceship and Complementarity of Behavioral Styles and Personality Traits Among College Roommates. Personality and Social Psychology Bulletin, 32(7), 907-916. https://doi.org/10.1177/0146167206287129

Moskowitz, D. S., Ho, M. R., \& Turcotte-Tremblay, A.-M. (2007). Contextual Influences on Interpersonal Complementarity. Personality and Social Psychology Bulletin, 33(8), 1051-1063. https://doi.org/10.1177/0146167207303024

Moskowitz, D. S., Russell, J. J., Sadikaj, G., \& Sutton, R. (2009). Measuring people intensively. Canadian Psychology/Psychologie Canadienne, 50(3), 131-140. https://doi.org/10.1037/a0016625 
Moskowitz, D. S., \& Sadikaj, G. (2012). Event-contingent recording. In M. R. Mehl \& T. S. Conner

(Eds.), Handbook of research methods for studying daily life (p. 160-175). The Guilford Press.

Moskowitz, D. S., Suh, E. J., \& Desaulniers, J. (1994). Situational influences on gender differences in agency and communion. Journal of Personality and Social Psychology, 66(4), 753-761.

https://doi.org/10.1037/0022-3514.66.4.753

Panc, T., Mihalcea, A., \& Panc, I. (2012). Self-Efficacy Survey: A new assessment tool. Procedia-Social and Behavioral Sciences, 33, 880-884. https://doi.org/10.1016/j.sbspro.2012.01.248

Parrigon, S., Woo, S. E., Tay, L., \& Wang, T. (2017). CAPTION-ing the situation: A lexically-derived taxonomy of psychological situation characteristics. Journal of Personality and Social Psychology, 112(4), 642-681. https://doi.org/10.1037/pspp0000111

Pennings, H. J. M., Brekelmans, M., Sadler, P., Claessens, L. C. A., van der Want, A. C., \& van Tartwijk, J. (2018). Interpersonal adaptation in teacher-student interaction. Learning and Instruction, 55, 41-57. https://doi.org/10.1016/j.learninstruc.2017.09.005

Pennings, H. J. M., van Tartwijk, J., Wubbels, T., Claessens, L. C. A., van der Want, A. C., \& Brekelmans, M. (2014). Real-time teacher-student interactions: A Dynamic Systems approach. Teaching and Teacher Education, 37, 183-193. https://doi.org/10.1016/i.tate.2013.07.016

Pincus, A. L., \& Ansell, E. B. (2003). Interpersonal Theory of Personality. In I. B. Weiner (Ed.), Handbook of Psychology (p. wei0509). John Wiley \& Sons, Inc. https://doi.org/10.1002/0471264385.wei0509

Pincus, A. L., Dawood, S., \& Hopwood, C. J. (2019). A Contemporary Interpersonal Reassessment of Madeline G. In C. J. Hopwood \& M. H. Waugh (Eds.), Personality Assessment Paradigms and Methods: A Collaborative Reassessment of Madeline G (1st ed.). Routledge. https://www.taylorfrancis.com/books/9781351388122 
Pincus, A. L., \& Hopwood, C. J. (2012). A Contemporary Interpersonal Model of Personality Pathology and Personality Disorder. In T. A. Widiger (Ed.), The Oxford Handbook of Personality Disorders (pp. 371-398). Oxford University Press. https://doi.org/10.1093/oxfordhb/9780199735013.013.0018

Pincus, A. L., Lukowitsky, M. R., Wright, A. G. C., \& Eichler, W. C. (2009). The interpersonal nexus of persons, situations, and psychopathology. Journal of Research in Personality, 43(2), 264-265. https://doi.org/10.1016/i.jrp.2008.12.029

Pincus, A. L., Sadler, P., Woody, E., Roche, M. J., Thomas, K. M., \& Wright, A. G. C. (2014). Multimethod assessment of interpersonal dynamics. In Multimethod clinical assessment. (pp. 51-91). Guilford Press.

Ramseyer, F., \& Tschacher, W. (2014). Nonverbal synchrony of head- and body-movement in psychotherapy: Different signals have different associations with outcome. Frontiers in Psychology, 5. https://doi.org/10.3389/fpsyg.2014.00979

Riso, L. P., Klein, D. N., Anderson, R. L., Ouimette, P. C., \& Lizardi, H. (1994). Concordance between patients and informants on the personality disorder examination. American Journal of Psychiatry, 151(4), 568573. https://doi.org/10.1176/ajp.151.4.568

Ross, J. M., Girard, J. M., Wright, A. G. C., Beeney, J. E., Scott, L. N., Hallquist, M. N., Lazarus, S. A., Stepp, S. D., \& Pilkonis, P. A. (2017). Momentary patterns of covariation between specific affects and interpersonal behavior: Linking relationship science and personality assessment. Psychological Assessment, 29(2), 123-134. https://doi.org/10.1037/pas0000338

Sadikaj, G., Russell, J. J., Moskowitz, D. S., \& Paris, J. (2010). Affect Dysregulation in Individuals With Borderline Personality Disorder: Persistence and Interpersonal Triggers. Journal of Personality Assessment, 92(6), 490-500. https://doi.org/10.1080/00223891.2010.513287

Sadler, P., Ethier, N., Gunn, G. R., Duong, D., \& Woody, E. (2009). Are we on the same wavelength? Interpersonal complementarity as shared cyclical patterns during interactions. Journal of Personality and Social Psychology, 97(6), 1005-1020. https://doi.org/10.1037/a0016232 
Sadler, P., Ethier, N., \& Woody, E. (2011). Interpersonal complementarity. In Handbook of interpersonal psychology: Theory, research, assessment, and therapeutic interventions. (pp. 123-142). John Wiley \& Sons, Inc.

Sadler, P., Woody, E., McDonald, K., Lizdek, I., \& Little, J. (2015). A Lot Can Happen in a Few Minutes:

Examining Dynamic Patterns Within an Interaction to Illuminate the Interpersonal Nature of Personality Disorders. Journal of Personality Disorders, 29(4), 526-546. https://doi.org/10.1521/pedi.2015.29.4.526

Schwartz, S. H. (2003). A proposal for measuring value orientations across nations. Questionnaire Development Package of the European Social Survey, 259-319.

Shavelson, R. J., Webb, N. M., \& Rowley, G. L. (1989). Generalizability theory. American Psychologist, 44(6), 922-932. https://doi.org/10.1037/0003-066X.44.6.922

Sherman, R. A., Rauthmann, J. F., Brown, N. A., Serfass, D. G., \& Jones, A. B. (2015). The independent effects of personality and situations on real-time expressions of behavior and emotion. Journal of Personality and Social Psychology, 109(5), 872-888. https://doi.org/10.1037/pspp0000036

Shiffman, S., Stone, A. A., \& Hufford, M. R. (2008). Ecological Momentary Assessment. Annual Review of Clinical Psychology, 4(1), 1-32. https://doi.org/10.1146/annurev.clinpsy.3.022806.091415

Spanier, G. B. (1976). Measuring Dyadic Adjustment: New Scales for Assessing the Quality of Marriage and Similar Dyads. Journal of Marriage and the Family, 38(1), 15. https://doi.org/10.2307/350547

Stone, A. A., \& Shiffman, S. (1994). Ecological Momentary Assessment (Ema) in Behavioral Medicine. Annals of Behavioral Medicine, 16(3), 199-202. https://doi.org/10.1093/abm/16.3.199

Stroud, C. B., Durbin, C. E., Saigal, S. D., \& Knobloch-Fedders, L. M. (2010). Normal and abnormal personality traits are associated with marital satisfaction for both men and women: An Actor-Partner Interdependence Model analysis. Journal of Research in Personality, 44(4), 466-477. https://doi.org/10.1016/j.jrp.2010.05.011 
Stroud, C. B., Durbin, C. E., Wilson, S., \& Mendelsohn, K. A. (2011). Spillover to triadic and dyadic systems in families with young children. Journal of Family Psychology, 25(6), 919-930. https://doi.org/10.1037/a0025443

Thijs, J., Koomen, H., Roorda, D., \& ten Hagen, J. (2011). Explaining teacher-student interactions in early childhood: An interpersonal theoretical approach. Journal of Applied Developmental Psychology, 32(1), 34-43. https://doi.org/10.1016/j.appdev.2010.10.002

Thomas, K. M., Hopwood, C. J., Woody, E., Ethier, N., \& Sadler, P. (2014). Momentary assessment of interpersonal process in psychotherapy. Journal of Counseling Psychology, 61(1), 1-14. https://doi.org/10.1037/a0034277

Tracey, T. J. G. (2004). Levels of Interpersonal Complementarity: A Simplex Representation. Personality and Social Psychology Bulletin, 30(9), 1211-1225. https://doi.org/10.1177/0146167204264075

Tracey, T. J. G., Bludworth, J., \& Glidden-Tracey, C. E. (2012). Are there parallel processes in psychotherapy supervision? An empirical examination. Psychotherapy, 49(3), 330-343. https://doi.org/10.1037/a0026246

Trull, T. J., \& Ebner-Priemer, U. (2013). Ambulatory Assessment. Annual Review of Clinical Psychology, 9(1), 151-176. https://doi.org/10.1146/annurev-clinpsy-050212-185510

Trull, T. J., \& Ebner-Priemer, U. (2014). The Role of Ambulatory Assessment in Psychological Science. Current Directions in Psychological Science, 23(6), 466-470. https://doi.org/10.1177/0963721414550706

Trull, T. J., \& Ebner-Priemer, U. W. (2020). Ambulatory assessment in psychopathology research: A review of recommended reporting guidelines and current practices. Journal of Abnormal Psychology, 129(1), 5663. https://doi.org/10.1037/abn0000473

Webb, N. M., \& Shavelson, R. J. (2005). Generalizability Theory: Overview. In B. S. Everitt \& D. C. Howell (Eds.), Encyclopedia of Statistics in Behavioral Science (p. bsa703). John Wiley \& Sons, Ltd. https://doi.org/10.1002/0470013192.bsa703 
Wiggins, J. S. (1979). A psychological taxonomy of trait-descriptive terms: The interpersonal domain. Journal of Personality and Social Psychology, 37(3), 395-412. https://doi.org/10.1037/0022-3514.37.3.395

Wiggins, J. S. (1991). Agency and communion as conceptual coordinates for the understanding and measurement of interpersonal behavior. In Thinking clearly about psychology: Essays in honor of Paul E. Meehl, Vol. 1: Matters of public interest; Vol. 2: Personality and psychopathology. (pp. 89-113). University of Minnesota Press.

Wilson, S., \& Durbin, C. E. (10/2012a). Dyadic Parent-Child Interaction During Early Childhood: Contributions of Parental and Child Personality Traits: Dyadic Parent-Child Interaction. Journal of Personality, 80(5), 1313-1338. https://doi.org/10.1111/j.1467-6494.2012.00789.x

Wilson, S., \& Durbin, C. E. (2012b). Parental personality disorder symptoms are associated with dysfunctional parent-child interactions during early childhood: A multilevel modeling analysis. Personality Disorders: Theory, Research, and Treatment, 3(1), 55-65. https://doi.org/10.1037/a0024245

Woods, W. C., \& Wright, A. G. (2019, January 16). Approaches to Modeling Interpersonal Complementarity in Intensive Longitudinal Data. https://doi.org/10.31234/osf.io/5xj7k

Wright, A.G.C., Pincus, A.L., \& Hopwood, C.J. (under review). Contemporary Integrative Interpersonal Theory: Integrating structure, dynamics, temporal scale, and levels of analysis.

Wright, A. G. C., \& Zimmermann, J. (2019). Applied ambulatory assessment: Integrating idiographic and nomothetic principles of measurement. Psychological Assessment, 31(12), 1467-1480. https://doi.org/10.1037/pas0000685 
Table 1. Observed Indices of Interpersonal Behaviors.

\begin{tabular}{|c|c|c|c|}
\hline Individual Behaviors & Computation & High Scores Indicate & Low Scores Indicate \\
\hline Average Warmth & $\begin{array}{l}\text { Mean of person's } \\
\text { warmth time-series }\end{array}$ & Warm; Connected & Cold; Distant \\
\hline Average Dominance & $\begin{array}{l}\text { Mean of a person's } \\
\text { dominance time-series }\end{array}$ & Assertive; Controlling & Passive; Submissive \\
\hline Warmth Variability & $\begin{array}{l}\text { Standard Deviation of person's } \\
\text { warmth time-series }\end{array}$ & Variability in communion/closeness & Constancy in communion/closeness \\
\hline Dominance Variability & $\begin{array}{l}\text { Standard Deviation of person's } \\
\text { dominance time-series }\end{array}$ & Variability in agency/assertiveness & Constancy in agency/assertiveness \\
\hline Warmth-Dominance Shape & $\begin{array}{c}\text { Correlation of person's } \\
\text { warmth and dominance time- } \\
\text { series }\end{array}$ & $\begin{array}{l}\text { Extraverted (warm-dominant) and/or } \\
\text { Withdrawn (cold-submissive) }\end{array}$ & $\begin{array}{l}\text { Agreeable (warm-submissive) and/or } \\
\text { Antagonistic (cold-dominant) }\end{array}$ \\
\hline \multicolumn{4}{|l|}{ Dyadic Behaviors } \\
\hline $\begin{array}{r}\text { Mean-Level } \\
\text { Warmth Complementarity }\end{array}$ & $\begin{array}{l}\text { Absolute value of the } \\
\text { discrepancy between spouses' } \\
\text { mean warmth }\end{array}$ & $\begin{array}{l}\text { Low Complementarity } \\
\text { (reciprocity) }\end{array}$ & $\begin{array}{l}\text { High Complementarity } \\
\text { (similarity) }\end{array}$ \\
\hline $\begin{array}{r}\text { Moment-to-Moment } \\
\text { Warmth Complementarity }\end{array}$ & $\begin{array}{l}\text { Correlation of spouses' } \\
\text { warmth time-series }\end{array}$ & $\begin{array}{l}\text { High Complementarity } \\
\text { (similarity) }\end{array}$ & $\begin{array}{l}\text { Low Complementarity } \\
\text { (reciprocity) }\end{array}$ \\
\hline $\begin{array}{r}\text { Mean-Level } \\
\text { Dominance Complementarity }\end{array}$ & $\begin{array}{l}\text { Absolute value of the } \\
\text { discrepancy between spouses' } \\
\text { mean dominance }\end{array}$ & $\begin{array}{l}\text { Low Complementarity } \\
\text { (similarity) }\end{array}$ & $\begin{array}{l}\text { High Complementarity } \\
\text { (reciprocity) }\end{array}$ \\
\hline $\begin{array}{r}\text { Moment-to-Moment Dominance } \\
\text { Complementarity }\end{array}$ & $\begin{array}{l}\text { Correlation of spouses' } \\
\text { dominance time-series }\end{array}$ & $\begin{array}{l}\text { Low Complementarity } \\
\text { (similarity) }\end{array}$ & $\begin{array}{l}\text { High Complementarity } \\
\text { (reciprocity) }\end{array}$ \\
\hline
\end{tabular}

Note: We collected time-series using the Continuous Assessment of Interpersonal Dynamics (CAID; Lizdek et al., 2011). Several precautions should be taken when correlating time-series data (e.g., Warner, 1998). We computed cross-correlation functions and examined correlations between relevant residual time-series data after accounting for any linear trends. Results did not substantively differ across these indices. 
Table 2. Means, (SDs), and Bivariate Correlations of Spouses' Interpersonal Behaviors across Situations.

\begin{tabular}{|c|c|c|c|c|c|}
\hline Individual Behaviors & Overall & Vacation & $\begin{array}{l}\text { Husband } \\
\text { Conflict }\end{array}$ & $\begin{array}{c}\text { Wife } \\
\text { Conflict }\end{array}$ & Best Things \\
\hline \multicolumn{6}{|l|}{ Average Warmth } \\
\hline Husbands' & $104.11_{(143.24)}$ & $144.90_{(140.12)}$ & $57.49_{(158.56)}$ & $58.06_{(130.89)}$ & $155.90_{(109.40)}$ \\
\hline Wives' & $117.79_{(140.51)}$ & $173.64_{(114.48)}$ & $65.18_{(155.54)}$ & $68.00_{(126.39)}$ & $164.42_{(124.57)}$ \\
\hline Spouse Correlation & $.69 * * *$ & $.52 * * *$ & $.69 * * *$ & $.71 * * *$ & $.70 * * *$ \\
\hline \multicolumn{6}{|l|}{ Average Dominance } \\
\hline Husbands' & $36.46_{(167.51)}$ & $65.92_{(170.30)}$ & $49.13_{(181.47)}$ & $26.42_{(153.97)}$ & $4.82_{(158.48)}$ \\
\hline Wives' & $42.26_{(162.15)}$ & $66.90_{(170.77)}$ & $36.08_{(178.02)}$ & $66.65_{(134.86)}$ & $-0.09_{(153.93)}$ \\
\hline Spouse Correlation & $-.54 * * *$ & $-.65 * * *$ & $-.63 * * *$ & $-.43 * * *$ & $-.49 * * *$ \\
\hline \multicolumn{6}{|l|}{ Warmth Variability } \\
\hline Husbands' & $61.95_{(35.00)}$ & $58.94_{(33.80)}$ & $74.08_{(40.58)}$ & $57.66_{(32.92)}$ & $57.15_{(29.29)}$ \\
\hline Wives' & $66.54_{(37.57)}$ & $59.16_{(29.40)}$ & $82.56_{(46.77)}$ & $65.69_{(35.67)}$ & $58.75_{(31.24)}$ \\
\hline Spouse Correlation & $.63 * * *$ & $.64 * * *$ & $.64 * * *$ & $.55^{* * *}$ & $.62 * * *$ \\
\hline \multicolumn{6}{|l|}{ Dominance Variability } \\
\hline Husbands' & $148.31_{(52.32)}$ & $120.04_{(37.32)}$ & $165.89_{(53.21)}$ & $155.56_{(57.67)}$ & $151.52_{(47.76)}$ \\
\hline Wives' & $147.06_{(53.88)}$ & $117.67_{(38.85)}$ & $168.74_{(54.10)}$ & $150.97_{(58.01)}$ & $150.64_{(50.04)}$ \\
\hline Spouse Correlation & $.71 * * *$ & $.47 * * *$ & $.70 * * *$ & $.72 * * *$ & $.73 * * *$ \\
\hline \multicolumn{6}{|l|}{ Warmth-Dominance Shape } \\
\hline Husbands' & $.04(.35)$ & $.07(.31)$ & $-.04(.34)$ & $-.05(.33)$ & $.19_{(.36)}$ \\
\hline Wives' & $-.00_{(.37)}$ & $.04_{(.31)}$ & $-.14_{(.39)}$ & $-.10_{(.35)}$ & $.20_{(.31)}$ \\
\hline Spouse Correlation & $.12^{* *}$ & -.07 & .15 & .01 & -.01 \\
\hline Dyadic Behaviors & Overall & Vacation & $\begin{array}{l}\text { Husband } \\
\text { Conflict }\end{array}$ & $\begin{array}{c}\text { Wife } \\
\text { Conflict }\end{array}$ & Best Things \\
\hline \multicolumn{6}{|l|}{ Warmth Complementarity } \\
\hline Mean-Level & $76.03_{(82.54)}$ & $87.53_{(95.93)}$ & $85.38(90.27)$ & $68.10_{(71.47)}$ & $63.29_{(67.33)}$ \\
\hline Moment-to-Moment & $.38_{(.29)}$ & $.39_{(.28)}$ & $.40_{(.29)}$ & $.39_{(.27)}$ & $.35_{(.32)}$ \\
\hline Complementarity Correlation & $-.20 * * *$ & -.10 & $-.36 * * *$ & -.14 & $-.25 * *$ \\
\hline \multicolumn{6}{|l|}{ Dominance Complementarity } \\
\hline Mean-Level & $139.52_{(108.92)}$ & $164.17_{(103.37)}$ & $138.59_{(107.92)}$ & $141.27_{(111.80)}$ & $114.44_{(107.87)}$ \\
\hline Moment-to-Moment & $-.54(.30)$ & $-.46_{(.29)}$ & $-.56_{(.29)}$ & $-.50_{(.32)}$ & $-.64_{(.26)}$ \\
\hline Complementarity Correlation & $.30 * * *$ & .16 & $.29 * * *$ & $.24 * *$ & $.44 * * *$ \\
\hline
\end{tabular}

Note: Standard deviations (SDs) were computed using the stats package (version 3.6.1) in R. SDs reflect the average variation in means across people within each situation and overall. Correlation coefficients indicate correlations between the variables in the two proceeding rows $\left({ }^{*} p<.05, * * p<.01, * * * p<.001\right)$. 
Table 3. Partitioning of Total Variance in Spouses' Interpersonal Behaviors (G Study Analyses).

\begin{tabular}{|c|c|c|c|c|c|c|c|c|c|}
\hline \multirow[b]{3}{*}{ Source of Variance } & \multicolumn{5}{|c|}{ Indices of Individual Behavior } & \multicolumn{4}{|c|}{ Indices of Dyadic Complementarity } \\
\hline & \multicolumn{2}{|c|}{ Mean } & \multicolumn{2}{|c|}{ Variability } & \multirow{2}{*}{$\begin{array}{c}\text { Shape } \\
\text { Warm-Dom }\end{array}$} & \multicolumn{2}{|c|}{ Mean-Level } & \multicolumn{2}{|c|}{ Moment-to-Moment } \\
\hline & Warm & Dom & Warm & Dom & & Warm & Dom & Warm & Dom \\
\hline$\sigma^{2}$ Person & $10.6 \% * * *$ & $42.8 \% * * *$ & $4.8 \% * * *$ & $2.0 \% * * *$ & $4.0 \% *$ & -- & -- & -- & -- \\
\hline$\sigma^{2}$ Couple & $25.1 \% * * *$ & $0.0 \%$ & $13.2 \% * * *$ & $7.5 \% * * *$ & $3.9 \% *$ & $22.3 \% * * *$ & $9.4 \% * * *$ & $6.0 \% * * *$ & $24.3 \% * * *$ \\
\hline$\sigma^{2}$ Situation & $9.6 \% * *$ & $1.7 \%$ & $4.3 \% *$ & $7.8 \% * *$ & $7.8 \% * *$ & $1.0 \%$ & $1.3 \%$ & $0.0 \%$ & $6.0 \% * * *$ \\
\hline$\sigma^{2}$ Rater & $4.7 \% * *$ & $1.9 \% * *$ & $17.8 \% * * *$ & $24.0 \% * * *$ & $6.1 \% * * *$ & $7.1 \% * * *$ & $18.3 \% * * *$ & $5.2 \% * *$ & $11.8 \% * * *$ \\
\hline$\sigma^{2}$ Person*Situation & $5.5 \% * * *$ & $24.1 \% * * *$ & $1.6 \% *$ & $3.1 \% * * *$ & $24.7 \% * * *$ & -- & -- & -- & -- \\
\hline$\sigma^{2}$ Couple*Situation & $12.1 \% * * *$ & $0.0 \%$ & $12.8 \% * * *$ & $11.5 \% * * *$ & $0.0 \%$ & $21.5 \% * * *$ & $17.6 \% * * *$ & $15.7 \% * * *$ & $19.3 \% * * *$ \\
\hline$\sigma^{2}$ Rater*Situation & $3.8 \% * * *$ & $1.8 \% * * *$ & $6.1 \% * * *$ & $9.6 \% * * *$ & $2.3 \% * * *$ & $1.8 \% * * *$ & $4.9 \% * * *$ & $4.6 \% * * *$ & $3.0 \% * * *$ \\
\hline$\sigma^{2}$ Person*Rater & $0.0 \%$ & $7.1 \% * * *$ & $0.0 \%$ & $0.0 \%$ & $3.8 \%$ & -- & -- & -- & -- \\
\hline$\sigma^{2}$ Couple*Rater & $9.7 \% * * *$ & $0.0 \%$ & $10.7 \% * * *$ & $11.0 \% * * *$ & $0.0 \%$ & $5.3 \% *$ & $3.8 \%$ & $0.0 \%$ & $3.7 \% *$ \\
\hline$\sigma^{2}$ Person Sex & $0.2 \%$ & $0.0 \%$ & $0.4 \%$ & $0.0 \%$ & $0.7 \%$ & -- & -- & -- & -- \\
\hline$\sigma^{2}$ Person Sex*Situation & $0.1 \%$ & $0.6 \% *$ & $0.3 \% *$ & $0.0 \%$ & $0.0 \%$ & -- & -- & -- & -- \\
\hline$\sigma^{2}$ Person Sex* Rater & $0.0 \%$ & $0.2 \%$ & $0.2 \%$ & $0.0 \%$ & $0.0 \%$ & -- & -- & -- & -- \\
\hline$\sigma^{2}$ Residual Error & $18.6 \%$ & $19.7 \%$ & $27.9 \%$ & $23.5 \%$ & $46.8 \%$ & $41.0 \%$ & $44.6 \%$ & $68.4 \%$ & $32.0 \%$ \\
\hline
\end{tabular}

Note: Possible sources of variance included persons $(n=274)$, couples $(n=137)$, situations $(n=4)$, rater $(n=10)$, person sex $(n=2)$, and their relevant interactions. Double dash marks (--) indicate not applicable (as person variables are not involved in computing dyadic complementarity variables). Values within each column sum to $100 \%$, within rounding error. Significance for random effects were determined with Likelihood-Ratio tests within each parameter using ImerTest package in $\mathrm{R}(* p<.05, * * p<.01, * * * p<.001)$. 
Table 4. Between- and Within- Person and Couple Consistency of Interpersonal Behaviors (D Study Analyses).

\begin{tabular}{|c|c|c|c|c|c|c|c|c|c|c|}
\hline & \multirow[b]{3}{*}{ Estimate of Consistency } & \multicolumn{5}{|c|}{ Indices of Individual Behavior } & \multicolumn{4}{|c|}{ Indices of Dyadic Complementarity } \\
\hline & & \multicolumn{2}{|c|}{ Average } & \multicolumn{2}{|c|}{ Variability } & \multirow{2}{*}{$\begin{array}{c}\text { Shape } \\
\text { Warm-Dom }\end{array}$} & \multicolumn{2}{|c|}{ Mean-Level } & \multicolumn{2}{|c|}{ Moment-to-Moment } \\
\hline & & Warm & Dom & Warm & Dom & & Warm & Dom & Warm & Dom \\
\hline $\mathrm{R}_{1 \mathrm{~F}}$ & $\begin{array}{l}\text { Between-person reliability of } \\
\text { observations within a situation }\end{array}$ & .69 & .90 & .41 & .25 & .30 & .70 & .48 & .26 & .76 \\
\hline $\mathrm{R}_{\mathrm{KF}}$ & $\begin{array}{l}\text { Between-person reliability of } \\
\text { observations across all situations }\end{array}$ & .96 & .99 & .87 & .77 & .79 & .96 & .90 & .78 & 97 \\
\hline $\mathrm{R}_{1 \mathrm{R}}$ & $\begin{array}{c}\text { Between-person reliability of } \\
\text { observations of different situations }\end{array}$ & .37 & .84 & .22 & .08 & .18 & .64 & .37 & .22 & .60 \\
\hline $\mathrm{R}_{\mathrm{c}}$ & $\begin{array}{l}\text { Within-person reliability of change } \\
\text { across situations }\end{array}$ & .75 & .92 & .36 & .57 & .84 & .84 & .80 & .70 & .86 \\
\hline
\end{tabular}

Note: Consistency in indices of complementarity reflect estimates of between- and within-couple influences, rather than between- and within-person influences. 
Figure 1. The Interpersonal Circumplex (IPC)

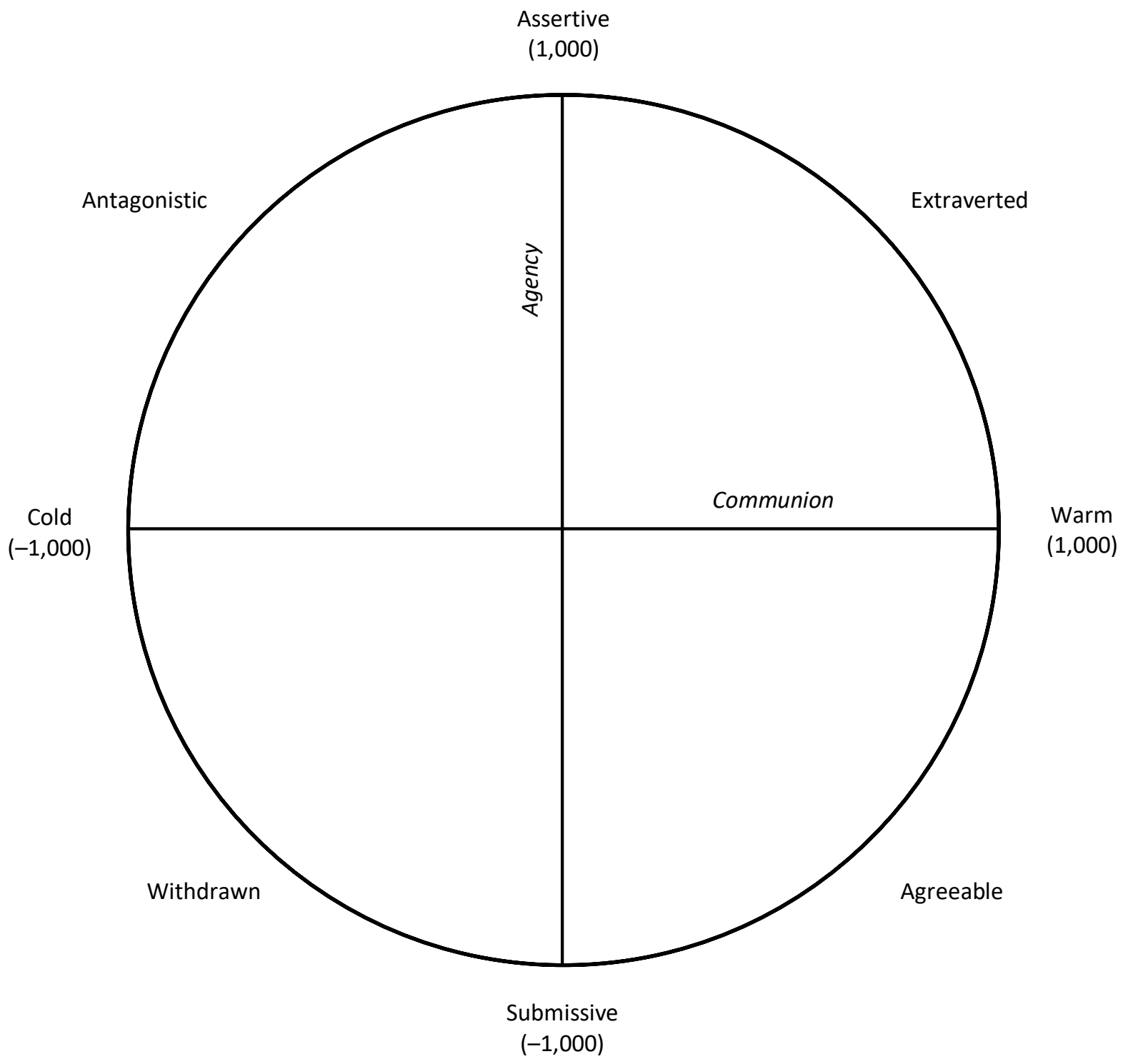

